\title{
6 \\ Collaborative Services in Informal Settlements: Social Innovation in a Pacified Favela in Rio de Janeiro
}

\author{
Carla Cipolla, Patricia Melo and Ezio Manzini
}

\section{Introduction}

Informal settlements, such as favelas (slums), are complex social ecosystems, characterised by their lack of basic services and by their particular social ties. Favelas in Rio de Janeiro are undergoing rapid changes, and new organisations and relationships are beginning to appear. This is largely as a result of the Rio de Janeiro government's policy of 'pacification' - a strategy to occupy the favelas formerly controlled by drug dealers, aimed at extending citizens' rights (and duties) in these areas (Fleury, 2012).

This chapter discusses these transformations, considering in particular if and how new services are emerging. This discussion is based on one significant case study - Light Recicla. Light Recicla, in Favela Santa Marta, Rio de Janeiro, is a service operated by the city's energy company that seeks to reduce the electricity bills of local residents by exchanging recyclable materials for energy credits, helping them to adjust to the new reality brought by pacification.

Under the framework of the pacification strategy, commercial companies and favela residents are establishing new relationships. Light Recicla aims to define a new mode of collaboration between the energy company, Light, and its customers that addresses this new set of social relations. Light's initiative is considered in this chapter as an example that highlights specific issues related to social innovation, particularly in terms of new social relations. The focus here is on social innovation 'as new ideas (products, services and models) that simultaneously meet social needs and create new social relationships or collaborations' (Murray et al., 2010, p. 3). In the context of the emergence of new market-based relations within the pacification process, the Light 
Recicla service is examined as a type of service that meets the demands of informal settlements via new, hybrid and collaborative services. It is also argued that the effectiveness of these new types of services is based on specific socio-cultural qualities.

In analysing informal settlements, this chapter draws on the work of the DESIS ${ }^{1}$ Thematic Cluster, ${ }^{2}$ 'Formal, Informal, Collaborative (IFC)', which sets out a typology of actions based on two main issues:

- Underserved communities. Informal settlements are complex social ecosystems, characterised by their lack of basic services (which has led to them being described as 'underserved' communities) and by the (relative) density of specific forms of social ties - from traditional ones, such as those of family, clan and village, to new ones that have emerged in the particular context of informal settlements, including those imposed by criminal gangs.

- Informal settlements in transformation. Driven by different factors, several informal settlements have recently entered a phase of rapid change (Echeverri and Orsini, 2011). In this changing environment, new organisations and forms of relationships, both inside the settlements and between them and the rest of the city, are appearing. In some places, such as Brazil, the starting point of this transformation has been the set of actions known as 'pacification' - the effects of which are still being evaluated (Fleury, 2012).

The working hypothesis presented in this chapter is aligned with a planning approach that, although not new, has only been widely adopted in the last decade. ${ }^{3}$ This hypothesis can be summarised in the following way:

- informal settlements can and must be improved;

- these improvements must make best possible use of existing physical and social resources;

- they should be enhanced by a set of local projects (at different scales) promoted and coordinated within a broader framework; and

- these local projects should be driven by and, in turn generate, social innovation.

Therefore, in the context of this chapter, pacification is not only seen as a public security project but also as a public policy enabling a myriad of projects to flourish, either in the favelas or in the neighbouring areas. The focus here is on one such project. 
To explore the development of new services in informal settlements, this chapter draws on a conceptual framework formulated in previous research, in which the notions of collaborative services and experiential versus relational interactions were developed.

The first notion came to light when research on design for social innovation (Manzini, 2007) identified types of service interactions that have been called collaborative services in social innovation cases (Manzini, 2008). The term 'collaborative' emerged from the fact that the qualities of interpersonal interactions were far removed from those of a delivery approach to services in which participants, including frontline employees (representing the organisation) and clients/users, have predefined roles (i.e., employees are active; clients are passive). These social innovations deconstructed the delivery approach to services, creating new collaborations and transforming all participants into active co-producers of commonly recognised benefits. They also gave rise to a special form of interpersonal interaction in services known as relational services (Cipolla and Manzini, 2009; Cipolla, 2012), where participants needed not only to be operationally active and collaborative, but also intentioned and willing to relate to, and interact with, one another in an intensely interpersonal way.

Based on Buber's $(1996 ; 2006)$ theoretical framework, these findings led to the definition of experiential versus relational services as polarities by which to identify the interpersonal qualities of services (Cipolla, 2004). Those relating to clearly designed roles and procedures for service actors, which predefine the range of possibilities for interpersonal encounters, are experiential, and those that increase the possibilities for (or even favour) unexpected interpersonal encounters, whether intentionally or otherwise, are relational.

On this basis, this chapter assumes two further working hypotheses. Given that informal settlements are underserved, it is proposed that:

- services in which all the people involved actively participate in achieving the final result are more likely to be successfully implemented in informal settlements than traditional delivery services; and

- collaboration can be both 'vertical' between service provider and service users/co-producers, and 'horizontal' between service users/ co-producers themselves.

This chapter presents the possibility of building on existing and new social ties to create a new generation of services - collaborative services able to involve resident communities in solving concrete problems of everyday life and in promoting the evolution of the existing mesh of 
social ties towards more open, flexible and transparent social networks. It does so with reference to a 'pacified' favela in Rio de Janeiro, and aims to understand better the features and socio-cultural qualities of a service recently introduced there. To address this objective, this chapter focuses on the following questions:

- What is the nature of the collaborations between service users and service provider and between service users themselves? How collaborative is the service overall?

- What are the features of core service encounters, the character of interpersonal interactions in the service and the interpersonal qualities of the service?

- What is the relationship between effectiveness and socio-cultural qualities, and what is the role played by social-cultural qualities in achieving the outcomes desired by the promoters and the users/ co-producers?

Field research was carried out on a service developed by the Electricity Company of Rio de Janeiro in pacified favelas, called 'Light Recicla'. Investigations were undertaken in all five favelas where the service was installed (Santa Marta, Rocinha, Chácara do Céu, Babilônia e Chapéu Mangueira and Cruzada S. Sebastião), while in-depth research was carried out in the Santa Marta favela, which was the first one to be pacified. To achieve the research objectives, ${ }^{4}$ a single case study in Santa Marta was completed. The qualitative research, carried out between March and August 2013, included:

- desk research, that examined news reports, reviews and official communication, including company reports;

- semi-structured interviews, which included talking to the company representative responsible for developing and implementing the project, and to those involved in the core service encounter (clients and agents); and

- observational research with direct observation of the service in its 'natural' setting (with particular focus on the characteristics of the service encounters), that included taking photographs (when allowed).

\section{The Light Recicla project}

Light Recicla was designed to support people living in pacified favelas in Rio de Janeiro who were in the process of obtaining legal access 


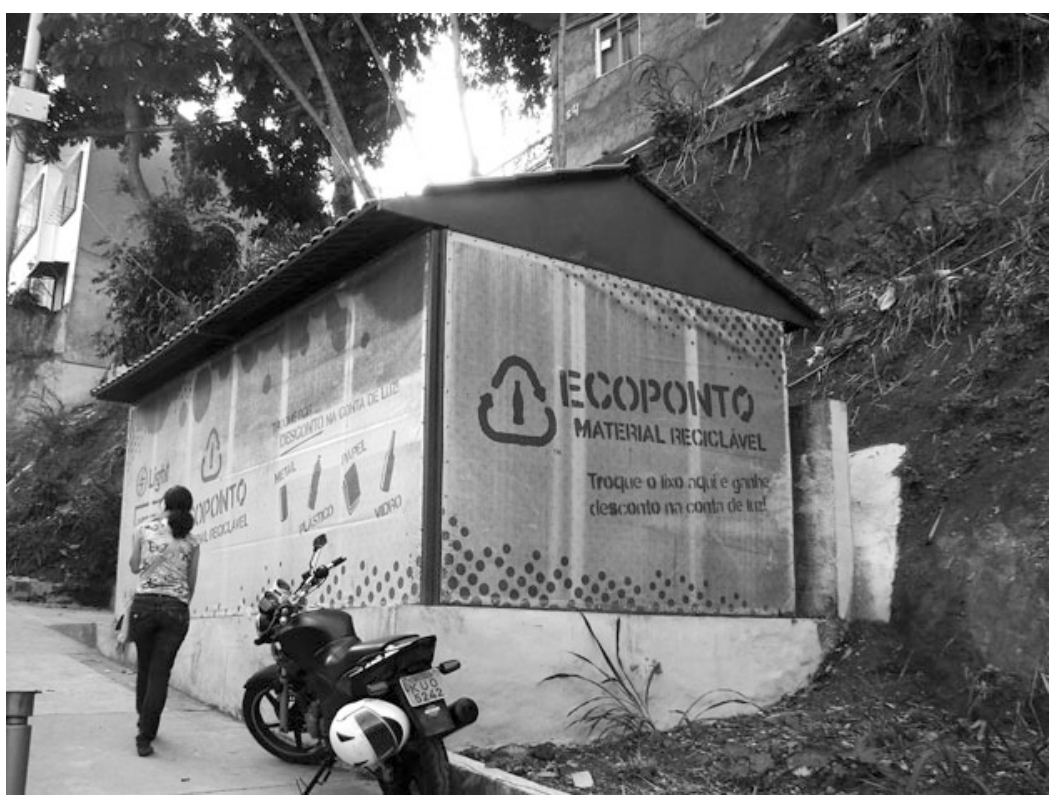

Figure 6.1 A Light Recicla collection point Source: Photograph @ Patricia Melo.

to energy. Light Recicla was designed as a complex service resulting from the combination of two services: delivery of electricity and collection of recyclable materials. The parent company - Light - itself managed the delivery of electricity. Meanwhile, a Light partner operated the collection of recyclable materials. Electricity was delivered in the standard way except for the payment system: citizens were requested to bring recyclable materials to dedicated collection points, where the value of these materials was converted into credits towards a discount in their next electricity bill.

Customers played an active role in the Light Recicla service: they collected the rubbish, washed it, separated it and brought it to the Collection Point, where the rubbish was weighed and the appropriate discount calculated and recorded in the system to appear on the next bill. Every consumer had a card with a user number that was used to record the discount. To participate in the project the user just needed to bring an energy bill to the Collection Point and to sign in. On the same day they could obtain a project card and could start bringing their rubbish to recycle, getting credits in their next monthly bill. Through the Light 


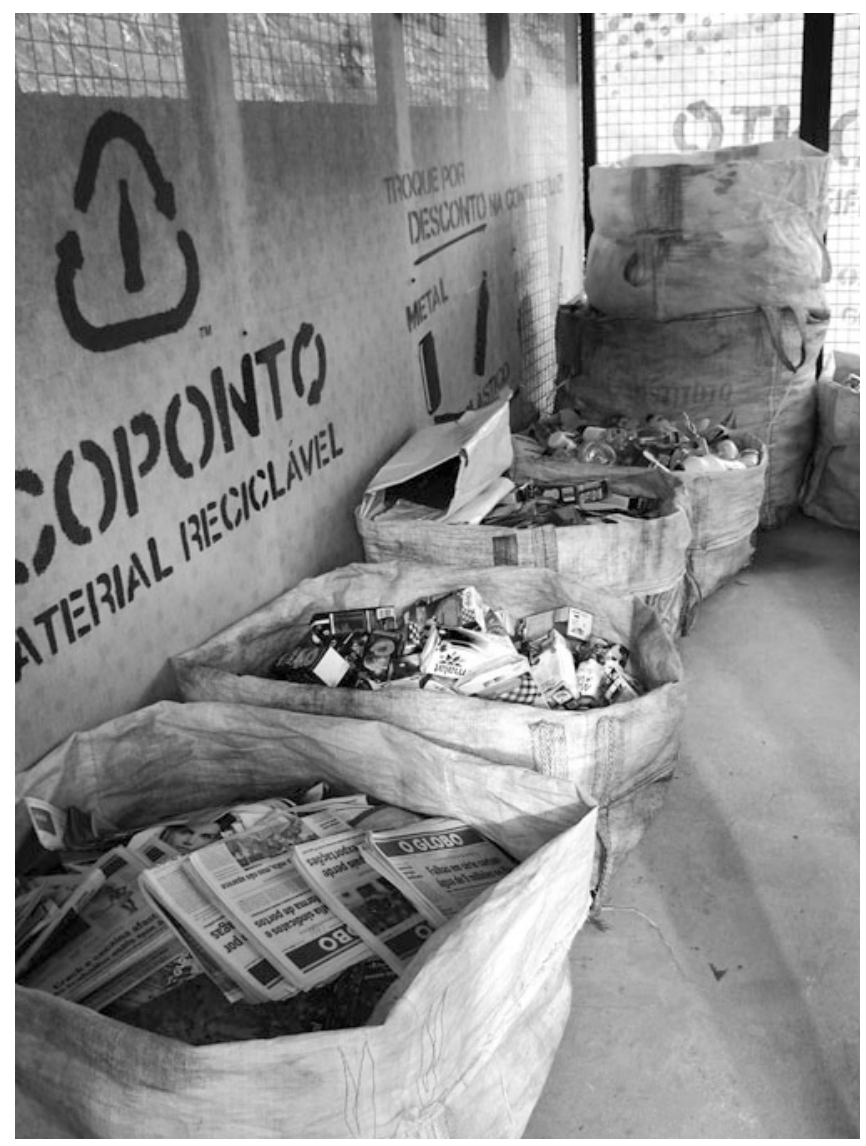

Figure 6.2 Recyclable materials separated at a Light Recicla collection point Source: Photograph @ Patricia Melo.

Recicla service, the company got paid for the energy it provided (even though the bills were paid in a way that was far from conventional).

\section{Background to the project}

Before the pacification process, heavily armed drug dealers dominated the favelas, making it difficult for the energy company to get access to the area and control how people were using the service. This resulted in only a few people paying their energy bills, creating a lose-lose situation: the energy company was losing because the energy it was providing was not being paid for and the favela residents were losing because 


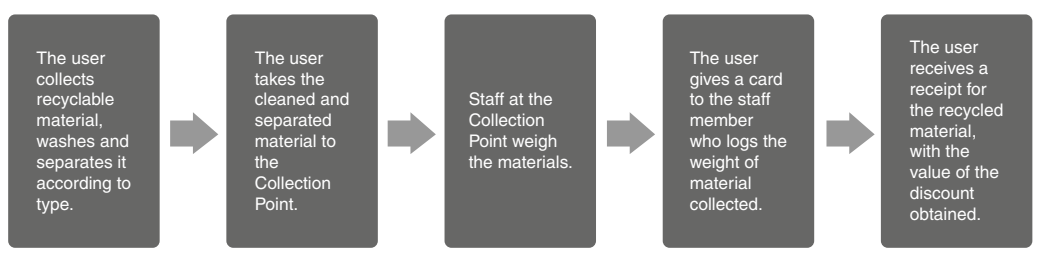

Figure 6.3 Light Recicla service process

Source: Drawn by the authors.

the service they were receiving was low quality. Moreover, since they were not paying for the service, they could not complain about any problems they encountered.

When the government permanently occupied the favelas with special police units that sought to establish a close and friendly relationship with locals, the energy company, Light, was able to offer services in a formal and legal way. This chapter will not discuss the pros and cons of the pacification model - rather it is assumed here that, as a result, the favelas are now more accessible and, as far as electricity delivery and consumption is concerned, this process brought about many changes in the consumer-provider relationship. This greater openness allowed Light to renew the power grid in favelas, to put new light meters in houses and to charge for electricity consumption in these communities. As a consequence of this formalisation of energy delivery, it was possible for people in the favelas to have a better quality energy service.

In turn, consumers were expected to start paying their bills regularly. However, in practice, this proved difficult. The cost of electricity was a new expense added to consumers' monthly budgets and, since they had no additional income, many found the payments a huge problem. An additional, related problem was that since they were not used to paying energy bills, consumers often had no concept of responsible consumption or of using energy in a way that they could ultimately afford.

Electricity theft was, therefore, a considerable problem for energy suppliers and providers. Aware of these issues, Light decided to try a different approach in pacified favelas, one based on dialogue and collaboration rather than punishing consumers.

Light's approach to tackling this problem through the Light Recicla project was aligned with research in the energy provision field that increasingly focussed on rethinking the relationship between energy suppliers/providers and users/customers. For example, on the basis of sixteen months of ethnographic fieldwork stretching over fifteen years 
in countries such as Zanzibar, Winther (2012) proposed that electricity theft is a relational issue. Her research aimed to show:

The merits of applying a grounded, socio-technical and relational analysis for understanding and addressing electricity theft in particular, and for realising sustainable energy systems in general. (p. 111)

Citing a previous study, she described how:

Conventional, top-down approaches to the problem tend to centre on either technical innovations such as smarter meters; managerial methods, for example, inspection, control and audits; or system changes, typically through privatisation of public energy companies. [However,] Experience shows that, taken alone, neither of these methods provides blueprint solutions to the problem. Broader and more contextually sensitive approaches are called for (Winther, 2012, p. 112).

\section{Design process}

Dialogue between Light and favela residents developed into a concrete project - Light Recicla - via an open exchange of experiences and ideas. Once the pacification process started, Light sent some of its employees into the communities to talk about how the company was going to formalise the electricity delivering process. In these visits the company started a dialogue with members of the community in order to make the transition from an informal to formal situation easier. One of the points raised was the amount of rubbish in favelas, much of which was recyclable.

This observation led the Light team to focus on a previous experience in the State of Ceará (Brazil) - developed by an electricity company called COELCE - where people exchanged recyclable materials for credits towards their electricity bill. This scheme was introduced to reduce waste in some areas of the state, using the reduction in energy bills as an incentive. Light Recicla was inspired by the Ceará project, but with a shift in focus from an environmental gain to a social gain. It was, therefore, an adaptation with a different focus, in a different context. Light's team realised that, if the Ceara project could be adapted to the pacified favelas in Rio de Janeiro, it would have a big impact given the new social demands brought by pacification. Waste, a huge problem in these areas, could become the solution that helped people pay their bills just as they were starting to gain legal access to an energy service. Thus, the project was also able to meet the demand for contextually sensitive 
approaches (Winther, 2012) in relationships with consumers, constituting a marked change to conventional company strategy.

\section{Project stakeholders and their motivations}

The main stakeholders in the project included the energy company, Light, energy users - the residents of the favela, and a range of other companies that acted as partners in the project.

Light believed that the best way to introduce a formal service in the previously informal settlement was to adopt a strategy that avoided being punitive and that embraced a more dialogical form of interaction. The company also believed that by building a good relationship with its customers, it would be able to reduce energy theft and bad debt overall, which would lead ultimately to a better economic result. An additional motivation for Light was that it was obliged by the terms of its contract with ANEEL (the National Electricity Agency in Brazil) to dedicate at least $0.5 \%$ of its net operating revenues each year to actions that aimed to combat electricity waste. Light Recicla helped fulfil this requirement. It also enhanced the brand value of Light, as it is could be presented as a project focussed on social benefit, enhancing the company's image within the pacification process.

Users' motivations within the project were of different kinds. Economic motivations were the most apparent - collecting recyclable materials in exchange for a reduction in their electricity bills. This was particularly true for users who were able to integrate the collection of recyclable materials into their own everyday work: for example, owners of local bars, food kiosk workers and janitors. These groups could collect large quantities of recyclables, allowing them to have large discounts or even offset their entire energy bill. However, deeper observation indicated that some domestic users considered the economic gains from the exchange too low and, therefore, engaged with the project because of the socio-cultural value of doing something good for themselves and for their community. In other words, some domestic users valued the environmental benefits brought by the project beyond the discount in their own bills, and this motivation appeared to be a meaningful driver for their active participation.

To operate the project, Light promoted a partnership with other companies: 3E Engenharia, which provided the ICT system through which the credits were recorded and managed the infrastructure of the collection points; Doe Seu Lixo, which received the waste from customers and took it to be recycled, while also managing the employees involved; and the Coopama, which was responsible for the collection and recycling 
of cooking oil. These companies were technically and economically involved in the project. The local government also cooperated with Light, granting the space and legal conditions for the project to function and recognising its potential benefit to the success of pacification.

\section{Findings and discussion}

The Light Recicla project has garnered some notable successes. In 2011, in its first year of operation, Light reported that Light Recicla gave an average discount per month of 22 reals per user (£5.79; Light, 2011, p. 82). The report noted that in 2012, the average discount per month was 40 reals per user (£10.52), an increase of almost $82 \%$ compared to 2011 , and the project had 1715 registered customers (Light, 2012, p. 36).

According to the company, Light Recicla had 4,898 registered customers by June 2013 , about $60 \%$ of whom were active - meaning they were collecting recyclable materials regularly. Light had granted Light Recicla's customers a total of $183,891.17$ reals $(£ 48,373.77)$ of credit against electricity bills. On average, between January and May 2013, $160,115.87 \mathrm{~kg}$ per month of material and 458.3 litres of cooking oil was collected across all collection points. Light reported that the company aimed to increase the number of beneficiary communities and users benefitting from the project.

In terms of the framework outlined above, research undertaken as part of this case study showed that Light Recicla could be considered a collaborative service, at least regarding the collection of recyclable material. It included both vertical and horizontal collaboration.

Vertical collaboration took place between service users (favela inhabitants) and the service provider (Light). This collaboration was a required condition for the collection of recyclable materials. Therefore, this component was necessarily a co-produced service: a service in which results could be achieved only if people actively participated and were motivated to engage in the service. Light Recicla aimed to open up a new relationship between the energy company and its users. The company-customer relationship in the favelas had historically been difficult and had led to distrust by both parties. The power company faced default and electricity theft, whilst customers were afraid of being overcharged, believing companies were benefitting to their detriment. Such feelings were particularly strong during the transition process, where users had no real idea of the value of their monthly consumption since it had not been formalised before. Despite residents being wary of their monthly bills, many users reported that Light Recicla was helping to 
build a more positive image of the company. Besides that, the company was also promoting consumer education concerning energy usage.

Horizontal collaboration is a form of collaboration between service users themselves. In the Light Recicla project, this kind of collaboration was not foreseen. Nevertheless, observation undertaken as part of this research showed that it was starting to take place in spontaneous, self-organised initiatives, when neighbours and family members helped each other. It could occur without payment or - as in one case observed by payment. In this case, a user called Benedito, who owned a bar near the collection point, observed that other users were not motivated to separate, clean and take their recyclable materials to the collection points. He started to collect other citizens' recyclables in exchange for half the value obtained in credits, developing a small business that increased his monthly income while helping others to lower their bills.

Moving on to consider the types of interactions or service encounters within the project, this research has shown that the Light Recicla service was conceived and implemented in such a way that personal interactions tended to happen following predefined procedures (in Buber's language, it was a collaborative service based on experiential interactions: 1996; 2006). Nevertheless, in practice, relational interactions appeared too. They were created in two main kinds of service encounter:

- encounters between service users and service frontline employees at the collection point, where the formalised interactions (in exchanging waste for electricity credits) were often surrounded by conversations of a more personal character. Here the frontline employees became personally involved with the users, despite the fact that they were not locals. Users brought their complaints to the frontline employees, since they represented the human face of the company; and

- encounters between peers, aimed at mutual help in collecting waste and delivering the material to the collection points, where some form of relational interactions were always needed. One of the users said he brought the waste of 'the grandmother of his girlfriend', who had time to clean up and organise the waste, but was not easily able to bring it to the collection point. In the case of Benedito and his small business, the social ties between him and his peers enabled his activity, as it was based also on trust. He prepared and delivered the recyclable materials of other users and discounts were credited to their accounts. Only later, and informally, by presenting the ticket showing the registered discount obtained, was he paid half the overall discount in cash for his contribution. 
Finally, the relationship between effectiveness and socio-cultural qualities was considered. Both service provider and service users had a clear economic motivation for taking part in the Light Recicla project and its success was mainly based on its practical effectiveness. The reduction of defaults on energy bills in the favelas can be considered an objective measure of effectiveness for both the company and its consumers. People in these areas were gradually required to act like any other citizen in Rio de Janeiro, where citizenship presupposes rights, but also duties. As regards electricity, regular bill payment also required an adequate connection to the power grid, which increased both the quality and safety of provision. With this in mind, it was reported by a company representative that the default rate fell to as little as $2 \%$ in the communities where the Light Recicla service was running.

This research suggests that the socio-cultural qualities expressed in the way the Light Recicla service was designed played an important role in making the service effective, although in different ways. These qualities can be summarised as follows:

- Openness: the service was based on an agreement in which different roles and procedures were clearly defined and could be easily communicated.

- Transparency: the whole service, and in particular the transaction of 'credits-for-recyclables', was visible and immediate, being directly related to the way service touch points were designed. The key items were the devices that weighed the recyclables, calculated their value, sent the information to the administration and printed, immediately, a receipt indicating the credit/discount obtained by the user. This is a key point since users in the favelas were typically wary of public service providers.

- Dignity: the service dealt with waste, but it was designed and managed to be clean, hospitable and friendly. This was clearly manifested in the nature of the service touch points and collection points, where staff were very well presented and efficient.

- Collaboration: the service introduced a complex idea of collaboration: formalised, vertical collaboration with the company, based on the previous three socio-cultural qualities, and more flexible, freer and more informal, horizontal collaboration on a personal-local scale.

\section{Conclusion}

The service analysed here was conceived as a collaborative service, based on vertical collaboration between service deliverers and service 
users/co-producers. In turn, this vertical collaboration, and the enabling systems on which it was based, enabled the users/co-producers to establish forms of horizontal collaboration with micro-businesses and/or mutual help activities through both experiential and relational interactions. The viability of the service was based on two main characteristics:

- a blend of vertical and horizontal collaboration, top-down and bottom-up initiatives, experiential and relational interactions. This blend was crucial to give the service the necessary transparency - through clear norms and procedures proposed by a legitimate, trustworthy authority - and embedded it in the local social fabric through horizontal collaboration and relational interaction; and

- a double link between its effectiveness and the socio-cultural qualities it generated, such as openness, transparency, dignity and collaboration. These qualities were fundamental for the success of the whole service. In turn, in practical terms, its success demonstrated and spread these qualities, that were essential in the situation facing the favelas.

The service was based on vertical, experiential interactions that, in turn, enabled horizontal, self-organised (often relational) ones. It can be defined as a hybrid collaborative service based on three pillars:

- structural features in terms of economic gains, effectiveness and the friendliness of its functioning;

- recognition of the positive meanings it conveyed and the sociocultural qualities that gave sense to active citizen participation; and

- the potential to enrich vertical collaboration with horizontal peerto-peer cooperation.

Given these empirical observations on a hybrid collaborative service model in an informal setting, the following lines of future research emerge. First, is this format viable in different contexts and application fields and, if so, with what limits? Second, can it contribute to improving the service levels in these settlements, because such services can be cheaper and/or more appropriate to their particular characteristics? Finally, can it contribute to creating a new kind of public space (and therefore open these settlements to other residents of the city)? 


\section{Notes}

1. DESIS - Design for Social Innovation for Sustainability - is a network of design labs based in design schools (or in other design-oriented universities) promoting social innovation towards sustainability. DESIS Labs are teams of professors, researchers and students who orient their didactic and research activities towards starting and/or facilitating social innovation processes.

2. Thematic Clusters are initiatives promoted by groups of DESIS Labs that have found a theme of common interest, and agreed to align and systemise their ongoing, programmed activities, with the aim of creating the most favourable conditions to conceive and enhance, locally and/or internationally, new and stronger outcomes. More about IFC thematic cluster on: <http://www.desisifc.org $>$ [Accessed 1 August 2013].

3. A well-known example in the United Kingdom of use of this approach in the design field has been promoted by the British Design Council in two projects: Design of the Time 2007 (Dott07) and Design of the Time Cornwall. These projects, addressing the social and economic dynamisation of regions in difficulty, have been pursued through a series of local projects emerging from careful attention to local demands and existing social capital (in terms of existing associations and enterprises already active on those topics). In Rio de Janeiro, an example of this approach - not related strictly to the design field is given in 'pacification': 'The strategy of pacification encompasses a first moment of military occupation, a second moment of installing a permanent police unity in the territory and a third one that aims to establish a dialogue among social actors in the territory and convey their demands to a policy network' (Fleury, 2012, p. 198).

4. 'A single case, meeting all of the conditions for testing the theory, can confirm, challenge, or extend the theory. The single case can then be used to determine whether a theory's propositions are correct or whether some alternative set of explanations might be more relevant' (Yin, 2013, p. 47).

\section{References}

Buber, M. (1996) I and Thou (W. Kaufmann, Trans.). New York: Simon and Schuster-Touchstone (Original work published 1921).

Buber, M. (2006) Between Man and Man (R. Gregor-Smith, Trans.). New York: Routledge Classics (Original work published 1947).

Cipolla, C. (2004) 'Tourist or Guest: Designing Tourism Experiences or Hospitality Relations?' Design Philosophy Papers, 2 (2): 103-13.

Cipolla, C. (2012) 'Solutions for Relational Services', in Miettinen, S. and Valtonen, A. (Org.), Service Design with Theory. Discussions on Change, Value and Methods. Rovaniemi: LUP - Lapland University Press.

Cipolla, C. and Manzini, E. (2009) 'Relational Services', Knowledge, Technology \& Policy, 22: 45-50.

Echeverri, A. and Orsini, F.M. (2011) 'Informalidad y Urbanismo Social en Medellín', Sostenible? 12.

Fleury, S. (2012) 'Militarização do social como estratégia de integração - o caso da UPP do Santa Marta', Sociologias, 14 (30): 194-222. 
Light (2011) Relatório de Sustentabilidade de 2011 [Sustainability Report 2011]. <http://www.relatoriolight.com.br/> [Accessed 1 August 2013].

Light (2012) Relatório de Sustentabilidade de 2012 [Sustainability Report 2012]. <http://www.relatoriolight.com.br/> [Accessed 1 August 2013].

Manzini, E. (2007) 'Design Research for Sustainable Social Innovation', in Michel, R. (ed.), Design Research Now. Basel: Birkhauser Verlag, pp. 233-45.

Manzini. E. (2008) 'Collaborative Organisations and Enabling Solutions. Social Innovation and Design for Sustainability', in Jegou, F. and Manzini, E. (eds), Collaborative Services. Social Innovation and Design for Sustainability. Milan: Edizioni Polidesign, pp. 29-41.

Murray, R., Caulier-Grice, J. and Mulgan, G. (2010) The Open Book of Social Innovation. London: The Young Foundation.

Winther, T. (2012) 'Electricity Theft As a Relational Issue: A Comparative Look at Zanzibar, Tanzania, and the Sunderban Islands, India', Energy for Sustainable Development, 16: 111-19.

Yin, R. (2013) Case Study Research. Design and Methods. California: Sage.

Except where otherwise noted, this work is licensed under a Creative Commons Attribution 3.0 Unported License. To view a copy of this license, visit http://creativecommons.org/licenses/by/3.0/ 